\title{
Human Capital Management Strategies in the Post COVID Era
}

\author{
Dr B Madhu Bala \\ Professor, \\ Aurora's PG College, Hyderabad-13, India
}

\begin{abstract}
COVID-19 pandemic has adversely affected both developed and developing countries and all industrial sectors across the globe. As a result of some cost cutting measures adopted by firms employees found regression in their career. This led to de-motivation and dissatisfaction among employees. This calls for reengineering of human resource practices and managing human capital more effectively and intelligently. Human capital management (HCM) refers to the set of human resource management practices that enhance the value of employees to the organization. The important elements of Human Capital management include Organizational vision and values, Strategic Goals and objectives and HCM leadership team. Success of HCM depends on effective management of human capital data, human capital initiatives and human capital development. Changing business environment conditions demand HR professionals to go in for intensive reskilling. Most of the organizations are using data analytics to integrate employee data from various divisions of the organization across the world to improve performance management, employee engagement and leadership development programs. In all modern organizations, HR teams are going through different phases of HR transformation. The HR practices that perfectly optimize the workforce competencies of one organization may not be best fit for another organization. Each organization has to find the right competencies to focus on with regard to talent acquisition, talent management and talent optimization. HR professionals need to enhance their skills to make best use of the predictive analytics to make intelligent employee decisions.
\end{abstract}

Keywords: Human Capital Management, Talent Optimization, Predictive Analytics

\section{Introduction}

COVID-19 outbreak led to fall in economic growth rate of many developing and developed countries across the world. Global economic growth rate is predicted to fall to $-4.9 \%$ in 2020 , compared to already poor growth rate of $2.9 \%$ in $2019^{\prime}$. This has a very adverse effect on business sustainability and employment. This has led freeze of salary hikes, reduction in salaries, temporary and permanent loss of employment to many employees. Many employees found themselves struggling to protect their job positions. This situation led to tremendous physical as well as psychological problems among employees. Human resource Managers need to find creative solutions to manage operations while ensuring the wellbeing of their employees and their performance.

\section{Human Capital Management in Organizations}

Human capital is the economic value that comes from employees' skills, knowledge and abilities. It is sum total of the money value of knowledge, talent and expertise of employees in the organization. Human capital is intangible. It includes employees' personal values and beliefs, work ethics, education and experience. Human capital can be measured and developed by organizational efforts. It can assure high return on investment if organization focuses on employee training and development and health and well-being programs.

\section{Human Capital Management (HCM)}

$\mathrm{HCM}$ is a set of practices related to acquisition, management and optimization of human resources. Effective HCM enables organizations to gain competitive advantage. HCM is a strategic management activity and requires commitment of top management to improve organizational culture, implement sixsigma, build global mindset among employees and reengineer organizational processes and functions. HCM extends beyond the functions of Human resource Management (HRM) as it seeks to optimize and 
maximize the value and ROI of the human capital in an organization. To perform these extended functions, many organizations are taking the help of technology enabled HCM Systems. HCM system employs broader perspective of organizational practices. For example, Induction program for new employees includes training in project-specific software tools as well as general on-boarding program.

\section{Components of Human Capital management}

The important elements of Human Capital management include the following:

1. Organizational vision and values: HCM system begins with defining and understanding the purpose for which company is established and values guiding its functioning. This will determine the workplace culture, employees' behavior and overall importance of the human capital in the organization.

2. Strategic Goals and objectives: Organization should establish long term goals which are specific, measurable, and time-bound. The human capital initiatives should be embedded in these organization's objectives. For example, a goal to increase employee job satisfaction scores by $25 \%$ will drive specific human capital initiatives like increasing employee engagement initiatives.

3. HCM leadership team: To manage human capital initiatives, it is preferable to have a HCM team that consists of cross-functional leaders. In large organizations the HR head will often drive HCM initiatives. In smaller organizations, this responsibility is taken up by CEO.

Success of HCM depends on effective management of human capital data, human capital initiatives and human capital development. Huge volumes of employee-related data like employee demographics, skills and abilities, appraisal data, compensation and benefits etc. need to be captured, stored, and made available in workforce analytics. From small start-ups to giant MNCs, all firms are maintaining HCM system.

\section{Role of HR Professionals}

It is observed that all organizations that emerged successfully out of recession period are those which harnessed their human capital to focus on talent, growth and innovation. They recognized that uncertainty is inevitable in business environment. The competitive advantage of firms lies in preparing human capital to be resilient to changing environment.

Changing business environment conditions demand HR professionals to go in for intensive re-skilling. The major challenges faced by HR managers include developing leaders, improving productivity and performance management, data management and analytics. According to Human Capital Trends Report 2016, developing potential leaders is always a strategic priority. However, only $30 \%$ of firms have made significant investment of time, efforts and money in this aspect. Most of the organizations are elevating the status of HR department from secondary to primary function. Top management is constantly monitoring the performance of HR function using various performance management metrics. Based on the result, management is taking necessary measures to continuously improve the effectiveness and efficiency of HR function.

Most of the organizations are using data analytics to integrate employee data from various divisions of the organization across the world to improve performance management, employee engagement and leadership development programs. Many organizations are reinventing people management practices and redesigning strategies for talent management and leadership development.

\section{HR Transformation}

In all modern organizations, HR teams are going through different phases of HR transformation.

The first phase involves making all administrative functions efficient, technology driven, and employee friendly. All the routine and non-core operations may be outsourced. In the second phase, HR management focuses on improving the impact of HR functions on productivity and efficiency of organizational operations. For this, the HR Head needs to work with other HR business partners to obtain insights on external and internal perspectives and introduce necessary HR initiatives to improve the productivity and 
efficiency. The third phase and final phase involves adopting and leveraging digital technologies including people analytics and HR automation to provide real-time interactive dashboards with human-centered design. There will be optimum level of efficiency in business operations and management will be free to focus on critical business issues like designing new workforce models, growth and innovation.

The biggest challenge before organizations now is to accelerate the process of transformation to achieve success and move ahead of competition. Different organizations use different paths and models to achieve the transformation. However, their efforts are often slowed down in the absence of proper change management initiatives, lack of best process practices and failure to adopt best suitable technology. Organizations need to identify any gaps in corporate level change initiatives by top leaders, business level leaders and project level leaders. The standard change management models like Kurt Lewins' model, Kotter's model or Prosci's ADKAR model may be used in this regard. The HR managers should identify the top ten processes that have a significant impact on the productivity and profitability of organization. These processes should be benchmarked against the best practices in the industry. The processes should be improved to equal or excel the best practices. The improved processes should be then incorporated into Artificial Intelligence (AI) driven HCM systems to achieve HR transformation. This will enable the organizations to transform the way they acquire, compensate, engage, retain, and promote the topperforming employees.

\section{Review of Literature}

Linet J A Obor (2017), examined that recruitment process guided by proper policies will encourage the employee retention in the long run and gives good corporate image to the organization. The effective recruitment process attracts skilled employees and retains them within the organization.

Uzzal Hossain \& Ishita Roy (2016) observed that the concept of human capital is concerned with the added value people provide for organizations. It emphasizes that competitive advantage is achieved by strategic investments in those assets through employee engagement and retention, talent management and learning and development programmes.

DR. MadhurimaLall (2007), examined that human resource practices affect the performance of the employee. Human resource has to assist the companies to adapt changing environment in the competitive labour market. Job improvement is a motivating factor for contributing towards the organizational performance.

Van Marrewijk and Joanna Timmers (2003) stated that Human Capital Management can be regarded as the umbrella term of three separate management disciplines - human asset management, human culture management and human potential management. Human Asset Management predominantly covers 'operations', culture management refers to managing people from different cultures and helping them adopt uniform organizational culture. Human Potential Management relates to development of employees. 'Human operations' and 'Human development' will improve productivity, support workplace climate, and stimulate human development. The HCM-activities strengthen the commitment, dedication and motivation of individual employees, while companies show an increase of their basic assets: material (financial performance), commercial, socialization and creative assets (or intellectual capital) (Hardjono, 1995).

Richard.W (2001) reiterated that the strategic human resources management or the human capital is means of gaining competitive advantage through one of the most important asset: its people.

Agarwal \& Ferret (2001) examined that the other sources of competitive advantage, like technology and physical resources are comparatively easier to emulate and transfer. - To create workforce that provide competitive advantage the firms create environment that provide knowledge, motivation, engagement that would be difficult for competitors to imitate. 


\section{Objectives}

1. To identify the factors influencing Human Capital Management in corporate firms.

2. To analyze the influence of Human Capital Management on Organizational performance.

\section{Hypothesis}

H0: There is no significant impact of Human Capital Management on Performance of corporate firms.

H1: There is significant impact of Human Capital Management on Performance of corporate firms.

\section{Research Methodology}

The study is based on both primary and secondary data. Primary data is obtained through structured Questionnaire. It consists of questions related to general information about respondents, questions related to factors influencing corporate firms' performance and questions related to human capital management practices. Likert's 5 scale was used in the questionnaire.

\section{Sample}

The researcher used convenience sampling method to collect the response from employees of corporate firms. The researcher considered 5 corporate firms whose annual revenues exceed US $\$ 10$ billion and 5 corporate firms whose annual revenues were below US \$10 billion but above US\$ \$3 billion. 125 questionnaires were given to employees from corporate firms earning above US $\$ 10$ billion and 125 questionnaires were given to employees from corporate firms earning below US $\$ 10$ billion but above US $\$ 3$ billion. 240 respondents returned the response sheets. However, there were only 223 responses that were fully filled and could be used for analysis. Hence, the sample size of the research is 223.

\section{Statistical Tools}

The statistical tools used for analysis are T test, ANOVA, Factor analysis and Multiple Regression Analysis.

\section{Data Analysis and Interpretation}

The present research is being conducted to identify various factors constituting Human capital Management and the impact of HCM practices on organization's performance. The KMO and Bartlett's Test was used to verify sample adequacy and Factor analysis was conducted to identify major factors constituting HCM.

The KMO and Bartlett's Test

\begin{tabular}{|l|l|r|}
\hline Kaiser-Meyer-Olkin Measure of Sampling Adequacy & & $\mathbf{0 . 4 4 6}$ \\
\hline Bartlett's Test of Sphericity & Approx.Chi-Square & 4828.846 \\
\hline & Df & 188 \\
\hline & Sig & 0.000 \\
\hline
\end{tabular}

From these results it can be interpreted that the sample taken is adequate.

By using factor analysis the 20 variables initially taken were reduced to 5 factors namely Recruitment and Selection, Training and Development, Performance Appraisal, Rewards and recognition and Employee relations management. These 5 factors have high statistical significance at $5 \%$ level. These 5 factors are independent variables and organizational performance is dependent factor.

Multiple regression analysis yielded following results

\begin{tabular}{|r|r|r|r|r|}
\hline Model & R & R Square & $\begin{array}{r}\text { Adjusted } \\
\text { R Square }\end{array}$ & $\begin{array}{c}\text { Std. Error of } \\
\text { the Estimate }\end{array}$ \\
\hline 1 & 0.652 & 0.424 & 0.418 & 0.444 \\
\hline
\end{tabular}

Predictors: P6, P10, P11, P19 
It can be interpreted that human capital management factors are independent and are capable of influencing organizational performance.

ANOVA results were as follows

\begin{tabular}{|l|r|r|r|r|r|}
\hline Model & Sum of Squares & Df & Mean Square & F & Sig \\
\hline Regression & 76.336 & 4 & 19.342 & 97.311 & 0.000 \\
\hline Residual & 105.178 & 528 & 0.196 & & \\
\hline Total & 181.525 & 536 & & & \\
\hline
\end{tabular}

Dependent Variable: Employee productivity

Predictors: (Constant), P6, P10, P11, P19

From the above table it is found that the F-value for the regression fit or the statistically significant at $5 \%$ level. This shows that the independent factors of human capital management are able to influence organizational performance.

The factors are individually estimated in the following table:

\section{Coefficients}

\begin{tabular}{|l|c|r|r|r|r|}
\hline & & \multicolumn{2}{|c|}{$\begin{array}{c}\text { Unstandardized } \\
\text { Coefficients }\end{array}$} & $\begin{array}{c}\text { Standardized } \\
\text { Coefficients }\end{array}$ & \\
\hline Model & B & Std. error & & $\mathbf{t}$ & sig \\
\hline Constant & 2,073 & 0.017 & & 107.587 & 0.000 \\
\hline P6 & 0.304 & 0.017 & 0.057 & 1.741 & 0.071 \\
\hline P10 & 0.331 & 0.017 & 0.582 & 17.579 & 0.000 \\
\hline P11 & 0.108 & 0.017 & 0.172 & 5.561 & 0.000 \\
\hline P19 & 0.125 & 0.017 & -0.22 & -6.479 & 0.000 \\
\hline
\end{tabular}

Dependent variable: Employee Productivity

From the above table, it can be interpreted that the five factors- Recruitment and Selection, Training and Development, Performance appraisal, Rewards and recognition and Employee relations management are able to influence performance of organization. Therefore, there is significant impact of Human Capital Management on Performance of corporate firms.

\section{Suggestions}

Organizations have to transform constantly to remain competitive and that transformation should not only include adopting advanced HR solutions but also commitment to invest in human capital development. Organizations should adopt technologies that are agile to accommodate future improvements in HR processes. The critical HR functions like talent acquisition, development and retention should not be outsourced by organizations. Organizations that are able to integrate human workforce and AI into superefficient teams can realize more value from HR transformation. Though employees enjoy the convenience and flexibility offered by work from home facility they still desire the social environment offered at workplace. Therefore, in future, organizations need to focus on technologies that can create this hybrid environment to facilitate communication, connectivity and collaboration. 


\section{Findings and Conclusion}

It is found from the research that in corporate firms, human capital management plays crucial role in improving organization's performance. It is concluded that proper recruitment and selection practices, training and development programs improve employee productivity. Proper reward and recognition of employees' efforts and Employee relations management contribute to employee retention and organization's productivity and profitability.

Human capital solutions enhance employee engagement and reduce employee attrition rates. HR digital transformation enables streamlining of induction and training processes for new hires and increases their pace of learning. Learning analytics are improving training effectiveness, providing personalized learning experiences and help in professional development of employees. HR executives are able to assist top management in creating business aligned people development strategies. The organizations that are failing to catch up with human capital transformation trends in the industry are fading and losing to competitors. Therefore there is no choice before top management but need to quickly integrate technology driven human capital systems into work routines to enhance human capabilities and transcend organizational capabilities. However, the huge challenge before organizations is to maximize benefits of HCM systems and minimize drawbacks.

\section{References}

[1] Jeff Schwartz et al., 2011 Human Capital Trends: Revolution/evolution, Deloitte, 2011.

[2] Tower Watson. (2012). The Global Workforce Study: Engagement at Risk: Driving Strong Performance in a Volatile Global Environment

[3] Marrewijk, M. van and Hardjono, T.W. (2003), "The European Corporate Sustainability Framework for managing complexity and corporate transition". Journal of Business Ethics .

[4] APQC. "HR Priorities, Performance, and Trends: Survey Results Report." APQC Knowledge Base, 2014.

[5] Gueutal, H., \& Stone, D. L. (Eds.) (2005). The brave new world of eHR: Human resources management in the digital age. San Francisco, CA: Jossey-Bass.

[6] Cappelli, P. (2001). Making the most of online recruiting. Harvard Business Review, 79, 139-146.

[7] OECD: Global economy faces gravest threat since the crisis as coronavirus spreads.2020;

[8] World Economic Forum: COVID-19's Workforce Impact. [Online]. Geneva: World Economic Forum, Strategic intelligence. 2020 